\title{
Gratification behaviour: A seizure mimicker in children
}

\author{
*Amit Kumar Satapathy ${ }^{1}$, Lipsa Das ${ }^{1}$, Basudev Biswal ${ }^{1}$ \\ Sri Lanka Journal of Child Health, 2020; 49(1): 75-76 \\ DOI: http://dx.doi.org/10.4038/sljch.v49i1.8903 \\ (Key words: Gratification behaviour, seizure, masturbation, pseudo seizure, infantile dyskinesia)
}

\section{Introduction}

Gratification behaviour or benign idiopathic infantile dyskinesia is a normal phenomenon seen in children of age group 3 months to 3 years ${ }^{1}$. It is often misdiagnosed as a seizure or movement disorder resulting in unnecessary investigations and treatment ${ }^{1}$. Here, we are reporting three cases of gratification disorder which were initially thought to be seizures but were subsequently diagnosed correctly and improved with parental counselling.

\section{Case 1}

A 13 month old baby girl presented with episodes of intermittently straightening the legs and keeping the legs crossed. These episodes occurred 8-10 times a day, each episode lasting for 5-10 minutes followed by crying for 5 minutes. It occurred during awakening and no episodes were documented while sleeping. There was no history of associated fever, frothing, up-rolling of eyeballs or incontinence.

Child was born to non-consanguineous parents and was first born without any adverse perinatal events. Developmental milestones were appropriate for her age. Physical examination was essentially normal. Child was assessed for a urinary tract infection initially which turned out to be normal. In view of the possibility of seizures, electroencephalography (EEG) was done but the recording was normal. In view of the typical features of a gratification disorder, child was admitted for observation. During hospitalisation, baby had similar episodes occurring frequently and became irritable when interrupted physically by restraining limbs. These episodes stopped abruptly when attention was diverted. Parents were counselled subsequently regarding the nature of the disorder and behavioural therapy was initiated by a psychologist.

${ }_{1}^{1}$ All India Institute of Medical Sciences,
Bhubaneswar, India
*Correspondence: amitkumar.satapathy@yahoo.co.in

https://orcid.org/0000-0003-1101-7847

(Received on 18 March 2018: Accepted after revision on 18 May 2018)

The authors declare that there are no conflicts of interest

Personal funding was used for the project.

Open Access Article published under the Creative

Commons Attribution CC-BY (c) (i) License

\section{Case 2}

A 10 month old girl presented with episodes of straightening legs with transient fixed gaze. It was associated with keeping the hand over genitalia for 1-2 minutes followed by crying. The developmental milestones were normal for her age without any significant adverse perinatal event. Physical examination was noncontributory. Urinary examination was normal. EEG did not show any abnormality. Psychiatry consultation was taken for behavioural therapy and parents were counselled for same. On follow up, child had decreased frequency of episodes.

\section{Case 3}

A 2 year old boy presented with episodes of extending the upper and lower limbs while lying in the prone position. These episodes were occurring 810 times a day. There was no history of frothing or incontinence or loss of consciousness following these episodes. Child attained developmental milestone appropriate for age. Child was evaluated outside and was started on antiepileptics. Initially he was started on sodium valproate and subsequently levetiracetam was added. There was no relief of symptoms. EEG was done multiple times and were all normal. Magnetic resonance imaging (MRI) of brain was also normal. During hospitalization, it was observed that episodes were terminated on diverting attention. Hence, the possibility of gratification disorder was entertained and behavioural therapy was initiated. Subsequently antiepileptics were tapered and stopped.

\section{Discussion}

Gratification behaviours are not uncommon in toddlers ${ }^{1}$. It is difficult to recognize in infants and toddlers because of lack of typical genital manipulation as seen in adults. Many a time they have been misdiagnosed as seizure disorder, paroxysmal movement disorder or gastrooesophageal reflux disease ${ }^{2}$. Nechay et al in a series of 31 cases reported seizure as the first diagnosis whereas in another series movement disorder was the initial diagnosis which was later confirmed to be gratification behaviour ${ }^{1,3}$. The typical features include pressure over perineum with typical posture of lower limbs associated with facial flushing, without alteration in consciousness level, recurrent episodes of variable duration which subsides with distraction ${ }^{4}$. Though difficult to differentiate from seizures, close observation of the episodes and 
videotaping help most of the time. Developmental history and detailed clinical examination, including neurological examination, are always normal in these children. Investigations like EEG and MRI are uninformative. The exact mechanism of these behaviours in infants is poorly understood. Counselling and education of the parents regarding the behaviour of their child remains the mainstay of treatment. They usually outgrow this behaviour with time ${ }^{5}$.

In our 3 cases, one has been treated as a seizure disorder with antiepileptics whereas in the other two cases the possibility of seizure vs urinary tract infection was thought and evaluated for same before diagnosis of gratification disorder was made. Parental counselling resulted in decrease in symptoms in all the cases. Awareness of gratification disorder among paediatricians not only helps in early diagnosis but also prevents them from doing unnecessary investigations.

\section{References}

1. Nechay A, Ross LM, Stephenson JB, O'Regan M. Gratification disorder ("infantile masturbation"): A review. Archives of Disease in Childhood 2004; 89:225-6. https://doi.org/10.1136/adc.2003.03210 2

PMid: 14977696 PMCid: PMC1719833

2. Bradley SJ. Childhood female masturbation. Canadian Medical Association Journal 1985; 132: 1165-6.
3. Fleisher DR, Morrison A. Masturbation mimicking abdominal pain or seizures in young girls. Journal of Pediatrics 1990; 116:810-4.

https://doi.org/10.1016/S00223476(05)8 2678-2.

4. Yang ML, Fullwood E, Goldstein J, Mink JW. Masturbation in infancy and early childhood presenting as a movement disorder: 12 Cases and a review of the literature. Pediatrics 2005; 116:1427-32.

https://doi.org/10.1542/peds.2005-0532 PMid: 16322167

5. Ibrahim A, Raymond B. Gratification disorder mimicking childhood epilepsy in an 18-month-old Nigerian girl: A case report and review of the literature. Indian Journal of Psychological Medicine 2013; 35:417-9 https://doi.org/10.4103/02537176.122247 PMid: 24379510 PMCid: PMC3868101 